\title{
A REVIEW OF DECELLULARIZED STEM CELL MATRIX: A NOVEL CELL EXPANSION SYSTEM FOR CARTILAGE TISSUE ENGINEERING
}

\author{
M. Pei ${ }^{1,2,3 *}$, J.T. Li ${ }^{1,2}$, M. Shoukry ${ }^{1,3}$ and Y. Zhang ${ }^{1,3}$ \\ ${ }^{1}$ Stem Cell and Tissue Engineering Laboratory, Department of Orthopaedics, West Virginia University, \\ Morgantown, WV, USA \\ ${ }^{2}$ Division of Exercise Physiology, West Virginia University, Morgantown, WV, USA \\ ${ }^{3}$ Mechanical and Aerospace Engineering, West Virginia University, Morgantown, WV, USA
}

\begin{abstract}
Cell-based therapy is a promising biological approach for the treatment of cartilage defects. Due to the small size of autologous cartilage samples available for cell transplantation in patients, cells need to be expanded to yield a sufficient cell number for cartilage repair. However, chondrocytes and adult stem cells tend to become replicatively senescent once they are expanded on conventional plastic flasks. Many studies demonstrate that the loss of cell properties is concomitant with the decreased cell proliferation capacity. This is a significant challenge for cartilage tissue engineering and regeneration. Despite much progress having been made in cell expansion, there are still concerns over expanded cell size and quality for cell transplantation applications. Recently, in vivo investigations in stem cell niches have suggested the importance of developing an in vitro stem cell microenvironment for cell expansion and tissue-specific differentiation. Our and other investigators' work indicates that a decellularized stem cell matrix (DSCM) may provide such an expansion system to yield large-quantity and high-quality cells for cartilage tissue engineering and regeneration. This review briefly introduces key parameters in an in vivo stem cell niche and focuses on our recent work on DSCM for its rejuvenating or reprograming effect on various adult stem cells and chondrocytes. Since research in DSCM is still in its infancy, we are only able to discuss some potential mechanisms of DSCM on cell proliferation and chondrogenic potential. Further investigations of the underlying mechanism and in vivo regeneration capacity will allow this approach to be used in clinics.
\end{abstract}

Key words: Decellularized matrix, synovium-derived stem cells, cell expansion, chondrogenic potential, cartilage tissue engineering, stem cell niche.

*Address for correspondence:

Ming Pei

Stem Cell and Tissue Engineering Laboratory

Department of Orthopaedics

West Virginia University

One Medical Center Drive, P.O.Box 9196

Morgantown, WV 26506-9196, USA.

E-mail: mpei@hsc.wvu.edu

\section{Introduction}

Articular cartilage is a unique, hypocellular, and avascular tissue, made mostly of extracellular collagens and proteoglycans; it has a limited ability to self-heal after trauma and degenerative disease (Redman et al., 2005). Since the late 1980 s, the most advanced and promising osteoarthritis treatment has been autologous chondrocyte transplantation (ACT) (Beningo et al., 2004). Treatment with ACT in full-thickness defects can offer early improvement shown to be sustained for up to ten years in most patients (Moseley et al., 2010); there is also some evidence that demonstrates better short- and mid-term outcomes with a possible return to pre-injury level in athletes (Harris et al., 2010). There are two different opinions in age-related ACT treatment effects: there is a minimal difference in patients both younger and older than 45 (Rosenberg et al., 2008) and there is significant improvement only for patients under 45 years of age (Nejadnik et al., 2010). In contrast, treatment with mesenchymal stem cells (MSCs) in patients over 45 had similar results to younger patients and offers the added advantage of not causing additional cartilage damage (Nejadnik et al., 2010).

A number of factors are thought to limit the potential of ACT-style treatments using chondrocytes or stem cells. Autologous cartilage biopsy needs further in vitro expansion due to the limited availability of cells. Replicative senescence occurs increasingly with population doubling (Hayflick, 1965), especially in cells from older compared to younger donors (Campisi and dÁdda di Fagagna, 2007). Articular chondrocytes display a decreased proliferation potential with age, exhibiting limited in vitro cell divisions (Evans and Georgescu, 1973) and decreased extracellular matrix (ECM) synthesis in an age-dependent decline as a consequence of decreased response to growth factors and cytokine stimulation (Loeser et al., 2000). Like articular chondrocytes, outside of their niche, adult stem cells lose their developmental potential quickly (Lin, 2002) and tend to either randomly differentiate or undergo apoptosis over time (Scadden, 2006). Thus, one of the major challenges in cartilage tissue engineering and regeneration is controlling the fate of articular chondrocytes and adult stem cells outside their natural environment. In native tissues, threedimensional (3D) microenvironments house stem cells and act to manage cellular behavior in a dynamic fashion via biochemical and biophysical cues. The stem cell niche exerts control over the intrinsic genetic pathways regulating the multi-potentiality and self-renewal ability of stem cells via extrinsic signals from the surrounding 
microenvironment (Zhang and Li, 2008). Thanks to current research progress in development biology, our work and that of other groups in reconstructing in vitro microenvironments to facilitate cell proliferation and lineage-specific differentiation suggests that this approach may be critical to overcoming the shortcomings of ACTstyle techniques for tissue engineering and regeneration of cartilage, intervertebral discs, and potentially other tissues. In this paper, we briefly review an in vivo stem cell niche and its key components and, for the first time, we summarize our recent work in the reconstruction of in vitro microenvironments using decellularized stem cell matrix (DSCM) for cell expansion to regenerate cartilage. Lastly, we briefly discuss some potential mechanisms underlying the cell rejuvenation effect from expansion substrate DSCM.

\section{Key parameters in an in vivo stem cell niche}

\section{Basic concept of in vivo stem cell niche}

A stem cell niche is a specific site in adult tissues where stem cells reside and undergo self-renewal and differentiation by producing large numbers of progeny. Ever since the concept of "niche" was proposed by Schofield in 1978 to describe the physiologically limited microenvironment of bone marrow in which the hematopoietic stem cells (HSCs) reside (Schofield, 1978), the niche hypothesis has been supported by a variety of co-culture experiments in vitro (Dexter et al., 1977; Rios and Williams, 1990; Moore et al., 1997; Li et al., 2004). Structurally, the niche is formed by supporting cells that provide a microenvironment for stem cells and the signals emanating from the supporting cells (Spradling et al., 2001; Lin, 2002; Li and Xie, 2005). However, it still remains a major challenge to accurately define the precise cellular components and anatomical structure of the niche.

\section{Effect of biochemical composition of ECM on embedded stem cells}

The ECM is primarily composed of various collagens, laminins, and glycoproteins serving as substrates for a myriad of adhesion molecules including integrins, cadherins, and discoidin domain receptors (Griffith and Swartz, 2006). Cell-matrix interaction-induced signaling constitutes a critical determinant of cell behavior, making the ECM composition a key factor in the stem cell niche. The integrins are a major family of ECM receptors that transmit information from the matrix to the cells, thereby playing a key role in the regulation of cell survival, proliferation, differentiation, and matrix remodeling (Loeser, 2002). The binding of ECM molecules to specific integrin receptors triggers activation of focal adhesion kinase (FAK) that in turn phosphorylates several proteins including Paxillin, Src homology 2 domain containing protein (SHC), and members of the SRC family kinases (Schlaepfer et al., 1999). Interestingly, inhibition of SRC-type kinases in both mouse and human embryonic stem cells (ESCs) were recently shown to cause differentiation (Anneren et al., 2004). In addition, both phosphatidylinositol 3-kinase (PI3-K) and mitogen-activated protein kinase (MAPK) pathways are also activated downstream of integrin (Chen et al., 1996; King et al., 1997).

\section{Effect of biophysical properties of ECM on resident stem cells (elasticity)}

A key challenge in stem cell research is to learn how to direct the differentiation of stem cells toward specific fates. Other than the components of the ECM, a variety of cues including biophysical factors, such as the stiffness of ECM and extrinsic mechanical factors as well as cell shape changes, are also capable of influencing stem cell proliferation, self-maintenance, and differentiation toward specific cell phenotypes. Recently, the elasticity of the matrix microenvironment was identified as regulating stem cell fate. By changing the stiffness of the substrate, human MSCs could be directed along neuronal, muscle, or bone lineages (Engler et al., 2006). Since then, substrate stiffness has been applied to modulate the proliferation and differentiation of ESCs (Evans et al., 2009; Jacot et al., 2010) as well as certain types of adult MSCs (Saha et al., 2008; Leipzig and Shoichet, 2009). The Ras superfamily, especially Rho subfamily members that are well known to regulate the cytoskeleton, cell growth, and transcription, is reported to be involved in substrate stiffness sensing (Peyton and Putnam, 2005). Rho-stimulated contractility drives stress fiber and focal adhesion formation and the up-regulation of $\alpha$-smooth muscle actin correlates with contractility on a rigid substrate (Chrzanowska-Wodnicka et al., 1996; Hinz et al., 2001). RhoA and downstream Rho kinase (ROCK) also mediate substrate rigidity-regulated $\mathrm{Ca}^{2+}$ oscillation, which determines the physiological functions of human MSCs (Kim et al., 2009). Rac1 is another Rho family protein that can be activated by myosin inhibition, which also has provided evidence for the critical role of contractility in substrate sensing (Pelham and Wang, 1997; Griffin et al., 2004). Interestingly, matrix stiffness could be an underlying mediator of growth factors, such as transforming growth factor beta (TGF- $\beta$ )-driven processes, regulating the equilibrium between storage and release of a host of matrix-bound growth factors (Wells and Disher, 2008).

Understanding has increased about how underlying matrix stiffness can guide stem cells toward a specific developmental lineage (Engler et al., 2006; Peyton et al., 2007), but matrix stiffness alone is likely to be insufficient to achieve complete terminal differentiation (Engler et al., 2006). Mounting evidence suggests that extrinsic mechanical factors can significantly influence the process of development and may play critical roles in controlling stem cell fate and lineage determination. For example, dynamic compression has been demonstrated to enhance chondrogenesis in studies conducted by a number of groups using scaffolds including agarose (Mouw et al., 2007; Thorpe et al., 2010), alginate (Campbell et al., 2006), hyaluronan-gelatin composites (Angele et al., 2004), and fibrin-polyurethane composites (Li et al., 2010). However, the control of stem cell biology through mechanical factors remains poorly understood and is receiving more attention in the developing field of regenerative medicine. The transduction of local mechano-stimuli into biochemical signals occurs through several signaling pathways, but 
studies have shown that transduction occurs locally at the cell periphery, even though the forces and the biochemical signals propagate throughout the cell (Choquet et al., 1997; Riveline et al. 2001; Galbraith et al., 2002; von Wichert et al., 2003). Complicated transduction processes, such as rigidity responses, involve several steps that can combine the transduction of force and/or geometry sensing with time (Discher et al., 2005; Giannone and Sheetz, 2006). Guanine nucleotide-exchange factors, $\mathrm{Ca}^{2+}$ ion channels, receptor-like protein tyrosine phosphatases, Src-family kinases, and membrane receptors have been surmised as early steps in force or geometry transduction (Katsumi et al., 2002; von Wichert et al., 2003; Munevar et al., 2004; Katsumi et al., 2005).

Cell shape is defined within the niche by the constraints imposed by the surrounding ECM on cells during development and adulthood (Folkman and Moscona, 1978; Chen et al., 1997). Alterations in adhesive interactions and crosstalk between the ECM and the cells work to define each other. Evidence suggests that physical control of cell shape alone can act as a potent regulator of cell signaling and lineage differentiation (Wozniak and Chen, 2009). As summarized in a recent review, the thorough understanding of the physical properties of ECM could facilitate the development of biomaterials to display and deliver stem cell regulatory signals in a precise and nearphysiological fashion, and serve as a powerful artificial microenvironment in which to study and instruct stem cell fate both in vitro and in vivo (Lutolf et al., 2009).

\section{Effect of 3D structure of ECM on resident stem cells}

The ECM comprises a scaffold of collagens and other structural proteins that are interlaced with proteoglycans which, together, control the local mechanical environment and contribute to the "stem cell niche" microenvironment through their own signaling moieties and their ability to bind growth factors, cytokines, enzymes, and other diffusible molecules. Compared to traditional twodimensional (2D) culture, culturing stem cells in 3D environments provides another dimension for external mechanical inputs and for cell adhesion, which dramatically affects integrin ligation, cell contraction, and associated intracellular signaling (Roskelley et al., 1994; Knight et al., 2000). Furthermore, the 3D environment might be necessary to model morphogenetic and remodeling events that occur over larger-length scales. The mechanisms by which nanotopographic cues derived from ECM influence stem cell proliferation and differentiation are not well investigated yet but appear to involve changes in cytoskeletal organization and structure, potentially in response to the geometry and size of the underlying features of the ECM. That is, changes in the feature size of the substrate may influence the clustering of integrins and other cell adhesion molecules, thus altering the number and distribution of focal adhesions. The composition and function of adhesions characterized in $3 \mathrm{D}$ matrices derived from tissues or cell culture were demonstrated to be different from focal and fibrillar adhesions characterized on $2 \mathrm{D}$ substrates in their content of $\alpha_{5} \beta_{1}$ and $\alpha_{\mathrm{v}} \beta_{3}$ integrins, paxillin, other cytoskeletal components, and tyrosine phosphorylation of FAK (Cukierman et al. 2001). Relative to $2 \mathrm{D}$ substrates, $3 \mathrm{D}$ matrix interactions also display enhanced cell biological activities and narrowed integrin usage.

\section{Soluble factors and their role on resident stem cells after immobilization on ECM}

Communication within the niche is essential for the maintenance of proper stem cell function and for determining the rate of stem cell self-renewal. Soluble factors may act locally or may diffuse throughout the niche to direct stem cell fate decisions. Studies indicate that supporting cells, which are located adjacent to stem cells, secrete soluble factors that are required for maintaining stem cell identity and for specifying stem cell self-renewal (Xie and Spradling, 1998; Kiger et al., 2001; Tulina and Matunis, 2001). Soluble factors, such as growth factors and cytokines, are important for the initiation and control of stem cell differentiation. A wide variety of soluble growth factors, such as basic fibroblast growth factor (FGF-2) (Chintala et al., 1994), TGF- $\beta$ (Paralkar et al., 1991), vascular endothelial growth factor, and hepatocyte growth factor (Ruhrberg et al., 2002), bind to a component of ECM [such as heparin sulfate], which greatly slows their diffusion and therefore serves to finetune their local concentrations and gradients (Paralkar et al., 1991; Ruhrberg et al., 2002). Matrix binding can create locally higher concentrations of autocrine growth factors (Tschumperlin et al., 2004), allowing smaller amounts of the factor to signal more effectively (Swartz, 2003).

\section{Environmental factors, such as low oxygen}

The physiological condition, including oxygen tension, is an important component of the stem cell microenvironment and has been shown to play a role in regulating both embryonic and adult stem cells. Low oxygen tensions (hypoxia) maintain undifferentiated states of embryonic, hematopoietic, mesenchymal, and neural stem cell phenotypes and also influence proliferation and cellfate commitment. Despite the presence of a decreased osteogenic and chondrogenic potential when induced to differentiate in hypoxic conditions (Malladi et al., 2006), adipose stem cells (ASCs) exhibited increased chondrocytic markers when expanded in hypoxic conditions and differentiated in normoxic cultures (Xu et al., 2007). The effect of hypoxia in committing ASCs to chondrocytes is thought to be mediated by hypoxiainducible transcription factor (HIF)-1 $\alpha$. Inhibition of HIF- $1 \alpha$ leads to decreased chondrogenic potential, normal osteogenic potential, and enhanced adipogenic potential (Malladi et al., 2007). The role of hypoxia and HIF-1 $\alpha$ in cell differentiation is tissue-specific, because HIF- $1 \alpha$ maintains the stem cells in an undifferentiated state, inhibits the differentiation of mesenchymal cells into osteoblasts, adipocytes, and myocytes, but stimulates the differentiation into chondrocytes (Salim et al., 2004; Gustafsson et al., 2005; Lin et al., 2006; Sainson and Harris, 2006). These data support the role of oxygen tension as an important factor in the determination of cell fate and maintenance of stemness in adipose and bone marrow derived MSCs. 


\section{Reconstruction of an in vitro microenvironment for cartilage tissue engineering and regeneration}

The customized "niches", consisting of a 3D matrix, soluble factors, regulated oxygen tension, and mechanical factors, can be used to imprint a "basal phenotype" on stem cells. The microenvironmental preconditioning step for stem cell fate modulation can be used to expand harvested cells while minimizing cell senescence and spontaneous differentiation and improving differentiation potential (Gregory et al., 2005). Such a microenvironment could restore plasticity to stem cells that have already undergone differentiation (Kai and Spradling, 2004). Despite the fact that synthetic matrices provide the highly controlled composition and structure, the lack of knowledge regarding mechanisms through which ECMs interact with cells limit their complexity. This can be addressed using cell-derived matrices, which have shown the potential to produce suitable basement membranes for in vitro expansion, which may provide deeper insights regarding cell-matrix interactions and differentiation. Currently, there are few studies investigating the effect of DSCM on cell proliferation and chondrogenic potential. Here, we summarize our recent work in this field.

\section{DSCM preparation}

Conventional plastic flasks are precoated with $0.2 \%$ gelatin (Sigma-Aldrich, St. Louis, MO, USA) at $37{ }^{\circ} \mathrm{C}$ for one hour and seeded with MSCs. After cells reach $90 \%$ confluence, $50 \mu \mathrm{M}$ L-ascorbic acid phosphate (Wako Chemicals USA Inc., Richmond, VA, USA) is added for 8 days. To remove the embedded cells, the deposited ECM is incubated with $0.5 \%$ Triton X-100 containing $20 \mathrm{mM}$ ammonium hydroxide at $37{ }^{\circ} \mathrm{C}$ for $5 \mathrm{~min}$. The DSCM can be stored for a couple of months at $4{ }^{\circ} \mathrm{C}$ in phosphate buffered saline containing $100 \mathrm{U} / \mathrm{mL}$ penicillin, $100 \mu \mathrm{g} /$ $\mathrm{mL}$ streptomycin, and $0.25 \mu \mathrm{g} / \mathrm{mL}$ fungizone.

\section{Rejuvenation effect of in vitro microenvironment on adult stem cells toward chondrogenesis}

Adult stem cells gradually lose their "stemness" once they are removed from their in vivo niche for plating in plastic flasks. Synovium-derived stem cells (SDSCs) are cartilage tissue-specific stem cells (Sakaguchi et al., 2005; Mochizuki et al., 2006; Pei et al., 2008; Dickhut et al., 2009; Segawa et al., 2009 Kurth et al., 2011). Porcine SDSCs were utilized as a model to reconstruct an in vitro 3D stem cell niche for chondrogenesis (He et al., 2009). After seeding on DSCM deposited by SDSCs, the initially wide and flat SDSCs became thin and spindle-shaped and were arranged in a 3D configuration with typical stem cell phenotypes. A dramatic increase in cell number and a greatly enhanced chondrogenic capacity were observed though, surprisingly, the DSCM-treated SDSCs did not display concomitantly improved adipogenic or osteogenic potentials. Thus, a tissue-specific stem cell can be used to prepare its own in vitro niche for stem cell proliferation while maintaining and enhancing its lineage-specific "stemness". To maximize cell yield during expansion, the in vitro microenvironment can be optimized by modulating oxygen tension and mitotic signaling in a tissue-specific DSCM deposited by SDSCs to rejuvenate expanded SDSC proliferation and chondrogenic potential (Li and Pei, 2011). Compared with the mitotic effect of FGF-2 on SDSCs, DSCM expansion greatly enhanced SDSC proliferation while retaining SDSCs' stem cell characteristics. More importantly, DSCM pretreatment yielded SDSC pellets with a comparable chondrogenic index [ratio of glycosaminoglycan (GAG) to DNA] to FGF-2 pretreatment, both of which were much higher than SDSC expansion on plastic flasks alone. Consistent with previous reports (Solchaga et al., 2005; Solchaga et al., 2010), FGF-2 pretreatment led to the highest GAG and DNA content; intriguingly, it also contributed to the highest expression level of hypertrophic marker genes. Surprisingly, the hypertrophic marker genes could be down-regulated if the pretreatment was combined with hypoxia or DSCM. The combination of hypoxia, FGF-2, and SDSC-derived DSCM contributed to the highest cell number in SDSC expansion. The above studies indicate that the 3D microenvironment for ex vivo expansion can be optimized to provide high-quality stem cells for stem cell-based cartilage defect repair.

MSCs from different sources have been shown to have different properties in terms of expansion capacity and lineage-specific differentiation (Sakaguchi et al., 2005). The challenge during chondrogenesis is to generate articular cartilage-like chondrocytes that do not undergo hypertrophy as a terminal differentiation stage. MSCs from bone marrow (BMSCs) appear to have a high propensity for cartilage hypertrophy and bone formation (Muraglia et al., 2000; Pelttari et al., 2006) and therefore may be ideal for bone tissue engineering through endochondral ossification. Our recent study assessed the rejuvenation effect of DSCM deposited by human BMSCs (hBMSCs) on hBMSC expansion and tissue-specific lineage differentiation potential (Pei et al., 2011). Passage 5 hBMSCs were expanded on DSCM or plastic flasks for one passage. DSCM expanded hBMSCs exhibited an enhanced proliferation capacity and acquired robust chondrogenic potential compared to those grown on plastic flasks. DSCM expansion decreased intracellular reactive oxygen species (ROS) and increased stage-specific embryonic antigen 4 (SSEA-4) expression in hBMSCs. DSCM expansion also up-regulated integrins $\alpha 2$ and $\beta 5$ and induced a sustained activation of extracellular signal-regulated kinase-1/2(Erk $1 / 2)$ and cyclin D1. Since inhibition of integrin $\alpha 2$ suppresses FAK activation and Erk $1 / 2$ phosphorylation (Sawhney et al., 2006), up-regulation of integrin $\alpha 2$ during DSCM expansion might be responsible for a sustained activation of Erk $1 / 2$ in hBMSCs. Up-regulation of TGF- $\beta$ receptor II during cell expansion and chondrogenic induction might be responsible for an enhanced chondrogenic potential in DSCM expanded hBMSCs. We also found that DSCM expanded hBMSCs had an increased osteogenic potential and decreased adipogenic capacity, which emphasizes BMSCs as a tissue specific stem cell for osteogenesis. DSCM deposited by hBMSCs may be a promising approach to expand BMSCs from elderly patients for the treatment of large-scale bone defects through endochondral bone formation. 
ASCs from infrapatellar fat pad (IPFP) are a promising source of stem cells for chondrogenesis (Wickham et al., 2003; Khan et al., 2007; Khan et al., 2008) and cartilage tissue engineering (Dragoo et al., 2003; Jurgens et al., 2009; Buckley et al., 2010). Our recent study assessed whether DSCM expansion could improve ASC proliferation and chondrogenic potential (He and Pei, 2011a). ASCs were separately expanded on plastic flasks, ASC-deposited DSCM, and SDSC-deposited DSCM. ASCs were centrifuged to form pellets and cultured in a serum-free chondrogenic medium with either TGF- $\beta 3$ or TGF- $\beta 3$ combined with bone morphogenetic protein 6 (BMP-6). Cell number yielded on DSCM expansion did not show a significant difference in deposition between ASCs and SDSCs but was 6 to 10 times that grown on plastic flasks. DSCM-expanded ASCs exhibited a lower level of intracellular ROS compared to those grown on plastic flasks. Typical chondrogenic markers, including type II collagen and GAG, were intensively distributed in the pellets from DSCM-expanded ASCs compared to those from plastic flask-grown cells. ASCs expanded on DSCM, either from ASCs or SDSCs, exhibited a similar chondrogenic index, which was significantly higher than that from ASCs grown on plastic flasks. Treatment with a combination of TGF- $\beta 3$ and BMP- 6 increased the ASC chondrogenic index $36 \%$ more than treatment with TGF- $\beta 3$ alone. Interestingly, DSCM pretreatment also decreased expanded ASC hypertrophic marker genes. DSCM deposited by either ASCs or SDSCs did not exhibit enhanced adipogenic differentiation of ASCs. This study indicates that the sequential application of DSCM for cell expansion and combined TGF- $\beta 3$ and BMP-6 for chondrogenic differentiation may be a promising approach for ASC-based cartilage tissue engineering and regeneration.

\section{Rejuvenation effect of in vitro microenvironment on adult chondrocytes}

DSCM has been demonstrated to rejuvenate expanded adult stem cells with enhanced proliferation and chondrogenic potential (He et al., 2009; Li and Pei, 2011; Pei et al., 2011). Our study also assessed the effect of DSCM deposited by SDSCs on articular chondrocyte expansion and maintenance of differentiation status and redifferentiation capacity (Pei and He, 2011). Passage 0 (P0) porcine articular chondrocytes were expanded for six passages on plastic flasks, SDSC-derived DSCM, or substrate switching from either plastic flask to DSCM or DSCM to plastic flask. DSCM not only greatly enhanced chondrocyte expansion but also delayed dedifferentiation of expanded chondrocytes. Intriguingly, compared to a dramatic decrease in CD90+/CD105+ cells and CD90+ cells, CD105+ cells dramatically increased when chondrocytes were plated on plastic flasks; on the contrary, DSCM expansion dramatically increased CD90+ cells and delayed the decrease of CD90+/CD105+ cells. Interestingly, chondrocytes expanded on DSCM also acquired a strong redifferentiation capacity, particularly in the pellets treated with TGF- $\beta 1$. In conclusion, the ratio of CD90 to CD105 may serve as a marker indicative of proliferation and redifferentiation capacity of dedifferentiated chondrocytes.
DSCM deposited by SDSCs provides a tissue-specific 3D microenvironment for ex vivo expansion of articular chondrocytes while retaining redifferentiation capacity, suggesting that DSCM may provide a novel approach for autologous chondrocyte-based cartilage repair.

Autologous disc cell-based therapy is a promising approach for intervertebral disc (IVD) regeneration. Unfortunately, the current in vitro expansion of nucleus pulposus (NP) cells in monolayer results in dedifferentiation of these cells. We also assessed the feasibility of using DSCM deposited by a tissue-specific stem cell to provide a 3D microenvironment for NP cell rejuvenation (He and Pei, 2011b). After plating for six passages on either plastic flasks or DSCM deposited by SDSCs, the expanded NP cells were evaluated for redifferentiation capacity. NP cells expanded on DSCM grew much faster with a smaller size and fibroblast-like shape compared to those on plastic flasks. DSCM-treated NP cells acquired an enhanced CD90 expression and higher mRNA levels of types I, II, and X collagen and aggrecan, as well as a robust redifferentiation capacity, evidenced by dramatically increased type II collagen, aggrecan, and Sox9 and decreased type I collagen for up to six passages. SDSC-derived DSCM can provide a tissue-specific microenvironment for the rejuvenation of NP cells with a higher proliferation rate and redifferentiation capacity. These characteristics may play a role in improving an autologous disc cell-based minimally invasive therapeutic approach toward physiological reconstruction of a biologically functional disc in the clinical setting.

\section{Potential Mechanism of DSCM on Cell Proliferation and Chondrogenic Potential}

The integrin family are key mediators for cell proliferation. Integrin-mediated cell adhesion is required for cell motility and affects cell proliferation (Schwartz and Assoian, 2001; Hynes, 2002). Ligands present in ECM, such as vitronectin, fibronectin, laminin, and collagen, are recognized by specific integrins, such as integrin $\alpha 5 \beta 1$ for fibronectin (Loeser, 2000). Integrin-ECM interaction can activate signaling cascades, such as Erk $1 / 2$, MAPK, PI3-K, and Akt (Sanders and Basson, 2000; Brockbank et al., 2005). It is agreed that sustained ERK activation requires cooperative signaling between receptor tyrosine kinases (RTKs) and integrins (Schwartz and Assoian, 2001). The induction of cyclin D1 mRNA has most frequently been attributed to the activation of ERKs (Roovers and Assoian, 2000). However, only a sustained ERK signal is not sufficient to induce cyclin D1 protein. PI3-K is also required for the expression and stability of cyclin D1 (Gille and Downward, 1999; Takuwa et al., 1999); in addition, FAK is an important regulator of cyclin D1. Overexpression of wild-type and dominant negative FAK cDNAs showed that integrin-dependent phosphorylation of FAK plays an important role in phosphorylation of ERK and induction of cyclin D1 (Zhao et al., 1998). Interaction of ECM molecules with adhesion receptor can directly activate growth factor receptor without the need for the receptor's soluble ligand (Howe et al., 1998). The ECM structure 
may also act as a molecular scaffold for the downstream component of signaling cascades, which allows more efficient propagation of the signals (Aplin et al., 1998). Another way by which ECM may affect cell proliferation is through harboring growth factors or growth factorbinding protein. The direct binding of growth factors to the ECM may affect the local concentration and the biological activity of the growth factors. On the contrary, growth factors also regulate modification and dynamic changes of ECM. ECM binds to the growth factors through the negatively charged heparin sulfate side chains of proteoglycans (Huhtala et al., 1999). The ECM serves as a reservoir, which could limit the movement and diffusion of soluble factors, and thus could sustain the cell growth and differentiation and other activities even when the soluble factors of cells have ceased.

Coordination between Wnt signals and other secreted signals contributes to the regulation of stem cell selfrenewal in tissue microenvironments (Klapholz-Brown et al. 2007). Wnt signals are not only involved in ECMmediated enhancement of stem cell proliferation, but also contribute to retaining or promoting differentiation potential. Czyz and Wobus reported evidence that the interaction of stem cells with ECM via integrins determines the expression of the signaling molecules BMP-4 and Wnt-1, resulting in the activation of the mesodermal and neuroectodermal lineage, respectively (Czyz and Wobus, 2001). Defective Wnt signaling, however, affects ECM synthesis, possibly being responsible for the etiology of the segmental premature aging disease HutchinsonGilford Progeria because mice exhibit skeletal defects and apoptosis in major blood vessels proximal to the heart (Hernandez et al. 2010). This study provided insights into the role of Wnt signaling and ECM in aging.

Despite the fact that the above studies demonstrated the role of Wnt in ECM-mediated proliferation and differentiation, there is no direct evidence suggesting the Wnt role in ECM enhancing stem cell chondrogenic potential. Wnt signaling plays an important role in chondrocyte maturation. Wnt inhibitors were reported to promote chondrogenic differentiation of human MSCs (Im and Quan, 2010). Moreover, Wnt signaling may play a "dual" role in chondrogenesis, depending on the specific Wnt ligand responsible for the signaling and the development stage when Wnt is engaged. During chondrogenesis in the chicken limb, Wnt5a delays the maturation of chondrocytes while Wnt4 accelerates the process (Hartmann and Tabin, 2000). Like Wnt5, Wnt7a also induces a chondro-inhibitory effect, which involves the MAPK pathway and activator protein-1 transcriptional activity (Tufan et al., 2002). Wnt14, another member of the Wnt family, is expressed in the chondrogenic region and has been reported to arrest and even reverse chondrogenic differentiation (Hartmann and Tabin, 2000). $\beta$-catenin, the central player in canonical Wnt signaling, is required during the early differentiation and late-stage maturation of chondrocytes, but the canonical pathway inhibits the progression of chondrocyte differentiation. Constitutively active $\beta$-catenin can prevent chicken chondrocytes from differentiation by down-regulating Sox 9 and type II collagen (Ryu et al., 2002); meanwhile, mice with elevated $\beta$-catenin activity resulting from secreted frizzled-related protein (sFRP1) deficiency exhibit accelerated chondrocyte maturation (Gaur et al., 2006).

During the differentiation and development period, Notch signaling determines many different fates of the cell. It is well established that integrins are major receptors for cell adhesion to ECM proteins in vertebrates; besides, integrins also make transmembrane connections to the cytoskeleton and activate many intracellular signaling pathways (Hynes, 2002). Notch 1 and $\beta 1$-integrins are cell surface receptors involved in the recognition of the niche that surrounds stem cells through cell-cell and cell-ECM interactions, respectively. Recently, a study reported that Notch and $\beta 1$-integrins are co-expressed and coordinated with epidermal growth factor receptor in maintaining neural stem cells (Campos et al., 2006). Another report demonstrated that the Notch pathway modulates the adhesion of bone marrow derived vascular precursor cells (BM-PC) to ECM via regulation of integrin $\alpha 3 \beta 1$; and that the Notch pathway inhibition on BM-PC impairs their capacity to stimulate endothelial cell tube formation on matrigel and to promote endothelial monolayer recovery following wounding in vitro (Caiado et al. 2008). Thus, the receptors for ECM such as integrins might act together with the Notch pathway to control cell responses to change the environment and the ECM of stem cells may affect stem cell maintenance and differentiation by affecting Notch signaling in a context- and time-dependent manner.

The chondrogenic effects of ECM on cells might be due to the regulation of Notch signal. A few studies have been conducted regarding the function of Notch signaling for chondrogenesis. Notch is expressed in the initial stage of chondrogenic cell differentiation and has a strong inhibitory effect on both proliferation and differentiation of the cells when activated (Watanabe et al., 2003). Notch signaling retains chondrocytes in an immature state (Karlsson et al., 2007). Blocked Notch signaling in murine limb bud cell micromass culture resulted in increased initiation of the condensation phase as well as induction of Sox 9 and type II collagen, indicating that Notch signaling may play an important role in chondrogenic differentiation by negatively regulating the initiation of prechondrogenic condensation (Fujimaki et al., 2006). This study also suggests that transient Notch signaling might be required for chondrogenesis, and that either blockage or activation of the Notch signaling pathway results in inhibited chondrogenesis (Fujimaki et al., 2006).

\section{Summary}

Autologous cell transplantation, or cell-based tissue engineering or regeneration, is a promising biological approach for the treatment of human disease due to the absence of disease transmission and immune rejection. However, the aging cell source from elderly patients and replicative senescence greatly hinder cell-based therapy. Reconstruction of an in vitro microenvironment is becoming an urgent and critical task to acquire a sufficient number of high-quality cells for cartilage tissue engineering and regeneration. DSCM provides a stem cell microenvironment resulting in expanded cells with 
acquired enhanced proliferation ability and chondrogenic potential. However, investigation of DSCM is still in its infancy. Many mysteries need to be addressed before this technology can be applied clinically. For example, what's the composition of DSCM? Are there any differences in DSCMs from different stem cells? What's the key component in DSCM that determines the fate of expanded cells? What's the signal transduction pathway guiding plated cell performance? How's the performance of DSCM expanded cells in vivo? Can ECM expanded cells resist the inflammatory environment post-implantation? All these concerns need be solved before this approach can be applied in clinics.

\section{Acknowledgements}

The authors thank Suzanne Smith and Brendan Jones for their help in editing the manuscript. This study was supported by a West Virginia University Faculty Startup Fund and research funds from the Musculoskeletal Transplant Foundation and the AO Foundation.

\section{References}

Angele P, Schumann D, Angele M, Kinner B, Englert C, Hente R, Fuchtmeier B, Nerlich M, Neumann C, Kujat $\mathrm{R}$ (2004) Cyclic, mechanical compression enhances chondrogenesis of mesenchymal progenitor cells in tissue engineering scaffolds. Biorheology 41: 335-346.

Anneren C, Cowan CA, Melton DA (2004) The src family of tyrosine kinases is important for embryonic stem cell self-renewal. J Biol Chem 279: 31590-31598.

Aplin AE, Howe A, Alahari SK, Juliano RL (1998) Signal transduction and signal modulation by cell adhesion receptors: the role of integrins, cadherins, immunoglobulincell adhesion molecules, and selectins. Pharmacol Rev 50: 197-263.

Beningo KA, Dembo M, Wang YL (2004) Responses of fibroblasts to anchorage of dorsal extracellular matrix receptors. Proc Natl Acad Sci USA 101: 18024-18029.

Brockbank EC, Bridges J, Marshall CJ, Sahai E (2005) Integrin beta1 is required for the invasive behavior but not proliferation of squamous cell carcinoma cells in vivo. $\mathrm{Br}$ J Cancer 92: 102-112.

Buckley CT, Vinardell T, Thorpe SD, Haugh MG, Jones E, McGonagle D, Kelly DJ (2010) Functional properties of cartilaginous tissues engineered from infrapatellar fat pad-derived mesenchymal stem cells. J Biomech 43: 920 926.

Caiado F, Real C, Carvalho T, Dias S (2008) Notch pathway modulation on bone marrow-derived vascular precursor cells regulates their angiogenic and wound healing potential. PLoS One 3: e3752.

Campbell JJ, Lee DA, Bader DL (2006) Dynamic compressive strain influences chondrogenic gene expression in human mesenchymal stem cells. Biorheology 43: 455-470.

Campisi J, dÁdda di Fagagna F (2007) Cellular senescence: When bad things happen to good cells. Nat Rev Mol Cell Biol 8: 729-740.
Campos LS, Decker L, Taylor V, Skarnes W (2006) Notch, epidermal growth factor receptor, and beta1-integrin pathways are coordinated in neural stem cells. J Biol Chem 281: 5300-5309.

Chen CS, Mrksich M, Huang S, Whitesides GM, Ingber DE (1997) Geometric control of cell life and death. Science 276: 1425-1428.

Chen Q, Lin TH, Der CJ, Juliano RL (1996) Integrinmediated activation of MEK and mitogen-activated protein kinase is independent of ras [corrected]. J Biol Chem 271: 18122-18127.

Chintala SK, Miller RR, McDevitt CA (1994) Basic fibroblast growth factor binds to heparan sulfate in the extracellular matrix of rat growth plate chondrocytes. Arch Biochem Biophys 310: 180-186.

Choquet D, Felsenfeld DP, Sheetz MP (1997) Extracellular matrix rigidity causes strengthening of integrin-cytoskeleton linkages. Cell 88: 39-48.

Chrzanowska-Wodnicka M, Burridge K (1996) Rhostimulated contractility drives the formation of stress fibers and focal adhesions. J Cell Biol 133: 1403-1415.

Cukierman E, Pankov R, Stevens DR, Yamada KM (2001) Taking cell-matrix adhesions to the third dimension. Science 294: 1708-1712.

Czyz J, Wobus A (2001) Embryonic stem cell differentiation: the role of extracellular factors. Differentiation 68: 167-174.

Dexter TM, Moore MA, Sheridan AP (1977) Maintenance of hemopoietic stem cells and production of differentiated progeny in allogeneic and semiallogeneic bone marrow chimeras in vitro. J Exp Med 145: 1612-1616.

Dickhut A, Pelttari K, Janicki P, Wagner W, Eckstein V, Egermann M, Richter W (2009) Calcification or dedifferentiation: requirement to lock mesenchymal stem cells in a desired differentiation stage. J Cell Physiol 219: 219-226.

Discher DE, Janmey P, Wang Y (2005) Tissue cells feel and respond to the stiffness of their substrate. Science 310: 1139-1143.

Dragoo JL, Samimi B, Zhu M, Hame SL, Thomas BJ, Lieberman JR, Hedrick MH, Benhaim P (2003) Tissueengineered cartilage and bone using stem cells from human infrapatellar fat pads. J Bone Joint Surg Br 85: 740-747.

Engler AJ, Sen S, Sweeney HL, Discher DE (2006) Matrix elasticity directs stem cell lineage specification. Cell 126: 677-689.

Evans CH, Georgescu HI (1973) Observations on the senescence of cells derived from articular cartilage. Mech Ageing Dev 22: 171-191.

Evans ND, Minelli C, Gentleman E, LaPointe V, Patankar SN, Kallivretaki M, Chen X, Roberts CJ, Stevens MM (2009) Substrate stiffness affects early differentiation events in embryonic stem cells. Eur Cell Mater 18: 1-13.

Folkman J, Moscona A (1978) Role of cell shape in growth control. Nature 273: 345-349.

Fujimaki R, Toyama Y, Hozumi N, Tezuka K (2006) Involvement of Notch signaling in initiation of prechondrogenic condensation and nodule formation in limb bud micromass cultures. J Bone Miner Metab 24: 191-198. 
Galbraith CG, Yamada KM, Sheetz MP (2002) The relationship between force and focal complex development. J Cell Biol 159: 695-705.

Gaur T, Rich L, Lengner CJ, Hussain S, Trevant B, Ayers D, Stein JL, Bodine PV, Komm BS, Stein GS, Lian JB (2006) Secreted frizzled related protein 1 regulates Wnt signaling for BMP2 induced chondrocyte differentiation. J Cell Physiol 208: 87-96.

Giannone G, Sheetz MP (2006) Substrate rigidity and force define form through tyrosine phophatase/kinase pathways. Trends Cell Biol 16: 213-223.

Gille H, Downward J (1999) Multiple ras effector pathways contribute to G(1) cell cycle progression. J Biol Chem 274: 22033-22040.

Gregory CA, Ylostalo J, Prockop DJ (2005) Adult bone marrow stem/progenitor cells (MSCs) are preconditioned by microenvironmental "niches" in culture: a two-stage hypothesis for regulation of MSC fate. Sci STKE 294: pe37.

Griffin MA, Sen S, Sweeney HL, Discher DE (2004) Adhesion-contractile balance in myocyte differentiation. J Cell Sci 117: 5855-5863.

Griffith LG, Swartz MA (2006) Capturing complex 3D tissue physiology in vitro. Nature Reviews 7: 211-224.

Gustafsson MV, Zheng X, Pereira T, Gradin K, Jin S, Lundkvist J, Ruas JL, Poellinger L, Lendahl U, Bondesson M (2005) Hypoxia requires notch signaling to maintain the undifferentiated cell state. Dev Cell 9: 617-628.

Harris JD, Brophy RH, Siston RA, Flanigan DC (2010) Treatment of chondral defects in the athlete's knee. Arthroscopy 26: 841-852.

Hartmann C, Tabin CJ (2000) Dual roles of Wnt signaling during chondrogenesis in the chicken limb. Development 127: 3141-3159.

Hayflick L (1965) The limited in vitro lifespan of human diploid cell strains. Exp Cell Res 37: 614-636.

He F, Chen XD, Pei M (2009) Reconstruction of an in vitro tissue-specific microenvironment to rejuvinate synovium-derived stem cells for cartilage tissue engineering. Tissue Eng Part A 15: 3809-3821.

He F, Pei M (2011a) Extracellular matrix enhances differentiation of adipose stem cells from infrapatellar fat pad toward chondrogenesis. J Tissue Eng Regen Med, in press.

He F, Pei M (2011b) Rejuvenation of nucleus pulposus cells using extracellular matrix deposited by synoviumderived stem cells. Spine, in press.

Hernandez L, Roux KJ, Wong ES, Mounkes LC, Mutalif R, Navasankari R, Rai B, Cool S, Jeong JW, Wang H, Lee HS, Kozlov S, Grunert M, Keeble T, Jones CM, Meta MD, Young SG, Daar IO, Burke B, Perantoni AO, Stewart CL (2010) Functional coupling between the extracellular matrix and nuclear lamina by Wnt signaling in progeria. Dev Cell 19: 413-425.

Hinz B, Celetta G, Tomasek JJ, Gabiani G, Chaponnier C (2001) Alpha-smooth muscle actin expression upregulates fibroblast contractile activity. Mol Biol Cell 12: 2730-2741.

Howe A, Aplin AE, Alahari SK, Juliano RL (1998) Integrin signaling and cell growth control. Curr Opin Cell Biol 10: 220-231.
Huhtala MT, Pentikäinen OT, Johnson MS (1999) A dimeric ternary complex of FGFR [correction of FGFR1], heparin and FGF-1 leads to an 'electrostatic sandwich' model for heparin binding. Structure 7: 699-709.

Hynes RO (2002) Integrins: bidirectional, allosteric signaling machines. Cell 110: 673-687.

Im GI, Quan Z (2010) The effects of Wnt inhibitors on the chondrogenesis from human mesenchymal stem cells. Tissue Eng Part A 16: 2405-2413.

Jacot JG, Kita-Matsuo H, Wei KA, Chen HS, Omens JH, Mercola M, McCulloch AD (2010) Cardiac myocyte force development during differentiation and maturation. Ann N Y Acad Sci 1188: 121-127.

Jurgens WJ, van Dijk A, Doulabi BZ, Niessen FB, Ritt MJ, van Milligen FJ, Helder MN (2009) Freshly isolated stromal cells from the infrapatellar fat pad are suitable for a one-step surgical procedure to regenerate cartilage tissue. Cytotherapy 11: 1052-1064.

Kai T, Spradling A (2004) Differentiating germ cells can revert into functional stem cells in Drosophilia melanogaster ovaries. Nature 428: 564-569.

Karlsson C, Jonsson M, Asp J, Brantsing C, Kageyama R, Lindahl A (2007) Notch and HES5 are regulated during human cartilage differentiation. Cell Tissue Res 327: 539551.

Katsumi A, Milanini J, Kiosses WB, del Pozo MA, Kaunas R, Chien S, Hahn KM, Schwartz MA (2002) Effects of cell tension on the small GTPase Rac. J Cell Biol 158: 153-164.

Katsumi A, Naoe T, Matsushita T, Kaibuchi K, Schwartz MA (2005) Integrin activation and matrix binding mediate cellular responses to mechanical stretch. J Biol Chem 280: 16546-16549.

Khan WS, Adesida AB, Hardingham TE (2007) Hypoxic conditions increase hypoxia-inducible transcription factor 2alpha and enhance chondrogenesis in stem cells from the infrapatellar fat pad of osteoarthritis patients. Arthritis Res Ther 9: R55.

Khan WS, Tew SR, Adesida AB, Hardingham TE (2008) Human infrapatellar fat pad-derived stem cells express the pericyte marker 3G5 and show enhanced chondrogenesis after expansion in fibroblast growth factor-2. Arthritis Res Ther 10: R74.

Kiger AA, Jones DL, Schulz C, Rogers MB, Fuller MT (2001) Stem cell self-renewal specified by JAK-STAT activation in response to a support cell cue. Science 294: 2542-2545.

Kim TJ, Seong J, Ouyang M, Sun J, Lu S, Hong JP, Wang N, Wang Y (2009) Substrate rigidity regulates $\mathrm{Ca}^{2+}$ oscillation via RhoA pathway in stem cells. J Cell Physiol 218: 285-293.

King WG, Mattaliano MD, Chan TO, Tsichlis PN, Brugge JS (1997) Phosphatidylinositol 3-kinase is required for integrin-stimulated AKT and raf-1/mitogen-activated protein kinase pathway activation. Mol Cell Biol 17: 44064418.

Klapholz-Brown Z, Walmsley GG, Nusse YM, Nusse R, Brown PO (2007) Transcriptional program induced by Wnt protein in human fibroblasts suggests mechanisms for cell cooperativity in defining tissue microenvironments. PLoS One 2: e945. 
Knight B, Laukaitis C, Akhtar N, Hotchin NA, Edlund M, Horwitz AR (2000) Visualizing muscle cell migration in situ. Curr Biol 10: 576-585.

Kurth TB, Dell'accio F, Crouch V, Augello A, Sharpe PT, De Bari C (2011) Functional mesenchymal stem cell niches in the adult knee joint synovium in vivo. Arthritis Rheum 63: 1289-1300.

Leipzig ND, Shoichet MS (2009) The effect of substrate stiffness on adult neural stem cell behavior. Biomaterials 30: 6867-6878.

Li JT, Pei M (2011) Optimization of an in vitro threedimensional microenvironment to reprogram synoviumderived stem cells for cartilage tissue engineering. Tissue Eng Part A 17: 703-712.

Li L, Xie T (2005) Stem cell niche: Structure and function. Annu Rev Cell Dev Biol 21: 605-631.

Li W, Johnson SA, Shelley WC, Yoder MC (2004) Hematopoietic stem cell repopulating ability can be maintained in vitro by some primary endothelial cells. Exp Hematol 32: 1226-1237.

Li Z, Yao SJ, Alini M, Stoddart MJ (2010) Chondrogenesis of human bone marrow mesenchymal stem cells in fibrin-polyurethane composites is modulated by frequency and amplitude of dynamic compression and shear stress. Tissue Eng Part A 16: 575-584.

Lin H (2002) The stem-cell niche theory: Lessons from flies. Nat Rev Genet 3: 931-940.

Lin Q, Lee YJ, Yun Z (2006) Differentiation arrest by hypoxia. J Biol Chem 281; 30678-30683.

Loeser RF (2000) Chondrocyte integrin expression and function. Biorheology 37: 109-116.

Loeser RF (2002) Integrins and cell signaling in chondrocytes. Biorheology 39: 119-124.

Loeser RF, Shanker G, Carlson CS, Gardin JF, Shelton BJ, Sonntag WE (2000) Reduction in the chondrocyte response to insulin-like growth factor 1 in ageing and osteoarthritis: studies in a non-human primate model of naturally occurring disease. Arthritis Rheum 43: 21102120 .

Lutolf MP, Gilbert PM, Blau HM (2009) Designing materials to direct stem-cell fate. Nature 462: 433-441.

Malladi P, Xu Y, Chiou M, Giaccia AJ, Longaker MT (2006) Effect of reduced oxygen tension on chondrogenesis and osteogenesis in adipose-derived mesenchymal cells. Am J Physiol Cell Physiol 290: C1139-1146.

Malladi P, Xu Y, Chiou M, Giaccia AJ, Longaker MT (2007) Hypoxia inducible factor-1alpha deficiency affects chondrogenesis of adipose-derived adult stromal cells. Tissue Eng 13: 1159-1171.

Mochizuki T, Muneta T, Sakaguchi Y, Nimura A, Yokoyama A, Koga H, Sekiya I (2006) Higher chondrogenic potential of fibrous synovium- and adipose synovium-derived cells compared with subcutaneous fatderived cells: distinguishing properties of mesenchymal stem cells in humans. Arthritis Rheum 54: 843-853.

Moore KA, Ema H, Lemischka IR (1997) In vitro maintenance of highly purified, transplantable hematopoietic stem cells. Blood 89: 4337-4347.

Moseley JB, Anderson AF, Browne JE, Mandelbaum BR, Micheli LJ, Fu F, Erggelet C (2010) Long-term durability of autologous chondrocyte implantation. Am J Sport Med 38: 238-246.

Mouw JK, Connelly JT, Wilson CG, Michael KE, Levenston ME (2007) Dynamic compression regulates the expression and synthesis of chondrocyte-specific matrix molecules in bone marrow stromal cells. Stem Cells 25: 655-663.

Munevar S, Wang YL, Dembo M (2004) Regulation of mechanical interactions between fibroblasts and the substratum by stretch-activated $\mathrm{Ca}^{2+}$ entry. J Cell Sci 117: 85-92.

Muraglia A, Cancedda R, Quarto R (2000) Clonal mesenchymal progenitors from human bone marrow differentiae in vitro according to a hierarchial model. J Cell Sci 113: 1161-1166.

Nejadnik H, Hui JH, Choong EPF, Tai BC, Lee EH (2010) Autologous bone marrow-derived mesenchymal stem cells versus autologous chondrocyte implantation. Am J Sport Med 38: 1110-1116.

Paralkar VM, Vukicevic S, Reddi AH (1991) Transforming growth factor beta type 1 binds to collagen IV of basement membrane matrix: Implications for development. Dev Biol 143: 303-308.

Pei M, He F (2011) Extracellular matrix deposited by synovium-derived stem cells delays replicative senescent chondrocyte dedifferentiation and enhances redifferentiation. J Cell Physiol, in press.

Pei M, He F, Vunjak-Novakovic G (2008) Synoviumderived stem cell-based chondrogenesis. Differentiation 76: 1044-1056.

Pei M, He F, Kish VL (2011) Expansion on extracellular matrix deposited by human bone marrow stromal cells facilitates stem cell proliferation and tissue-specific lineage potential. Tissue Eng Part A, in press.

Pelham RJ Jr, Wang Y (1997) Cell locomotion and focal adhesions are regulated by substrate flexibility. Proc Natl Acad Sci USA 94: 13661-13665.

Pelttari K, Winter A, Steck E, Goetzke K, Hennig T, Ochs BG, Aigner T, Richter W (2006) Premature induction of hypertrophy during in vitro chondrogenesis of human mesenchymal stem cells correlates with calcification and vascular invasion after ectopic transplantation in SCID mice. Arthritis Rheum 54: 3254-3266.

Peyton SR, Putnam AJ (2005) Extracellular matrix rigidity governs smooth muscle cell motility in a biphasic fashion. J Cell Physiol 204: 198-209.

Peyton SR, Ghajar CM, Khatiwala CB, Putnam AJ (2007) The emergence of ECM mechanics and cytoskeletal tension as important regulators of cell function. Cell Biochem Biophys 47: 300-320.

Redman SN, Oldfield SF, Archer CW (2005) Current strategies for articular cartilage repair. Eur Cell Mater 9: 23-32.

Rios M, Williams DA (1990) Systematic analysis of the ability of stromal cell lines derived from different murine adult tissues to support maintenance of hematopoietic stem cells in vitro. J Cell Physiol 145: 434-443.

Riveline D, Zamir E, Balaban NQ, Schwarz US, Ishizaki T, Narumiya S, Kam Z, Geiger B, Bershadsky AD (2001) Focal contacts as mechanosensors:externally 
applied local mechanical force induces growth of focal contacts by an mDia1-dependent and ROCK-independent mechanism. J Cell Biol 153: 1175-1186.

Roovers K, Assoian RK (2000) Integrating the MAP kinase signal into the G1 phase cell cycle machinery. Bioessays 22: 818-826.

Rosenberg RE, Gomoll AH, Bryant T, Minas T (2008) Repair of large chondral defects of the knee with autologous chondrocyte implantation in patients 45 years or older. Am J Sports Med 36: 2336-2344.

Roskelley CD, Desprez PY, Bissell MJ (1994) Extracellular matrix-dependent tissue-specific gene expression in mammary epithelial cells requires both physical and biochemical signal transduction. Proc Natl Acad Sci USA 91: 12378-12382.

Ruhrberg C, Gerhardt H, Golding M, Watson R, Ioannidou S, Fujisawa H, Betsholtz C, Shima DT (2002) Spatially restricted patterning cues provided by heparin-binding VEGF-A control blood vessel branching morphogenesis. Genes Dev 16: 2684-2698.

Ryu JH, Kim SJ, Kim SH, Oh CD, Hwang SG, Chun CH, Oh SH, Seong JK, Huh TL, Chun JS (2002) Regulation of the chondrocyte phenotype by beta-catenin. Development 129: 5541-5550.

Saha K, Keung AJ, Irwin EF, Li Y, Little L, Schaffer DV, Healy KE (2008) Substrate modulus directs neural stem cell behavior. Biophys J 95: 4426-4438.

Sainson RC, Harris AL (2006) Hypoxia-regulated differentiation: Let's step it up a notch. Trends Mol Med 12: 141-143.

Sakaguchi Y, Sekiya I, Yagishita K, Muneta T (2005) Comparison of human stem cells derived from various mesenchymal tissues: superiority of synovium as a cell source. Arthritis Rheum 52: 2521-2529.

Salim A, Nacamuli RP, Morgan EF, Giaccia AJ, Longaker MT (2004) Transient changes in oxygen tension inhibit osteogenic differentiation and Runx2 expression in osteoblasts. J Biol Chem 279: 40007-40016.

Sanders MA, Basson MD (2000) Collagen IVdependent ERK activation in human Caco-2 intestinal epithelial cells requires focal adhesion kinase. J Biol Chem 275: 38040-38047.

Sawhney RS, Cookson MM, Omar Y, Hauser J, Brattain MG (2006) Integrin alpha2-mediated ERK and calpain activation play a critical role in cell adhesion and motility via focal adhesion kinase signaling: identification of a novel signaling pathway. J Biol Chem 281: 8497-8510.

Scadden DT (2006) The stem-cell niche as an entity of action. Nature 441: 1075-1079.

Schlaepfer DD, Hauck CR, Sieg DJ (1999) Signaling through focal adhesion kinase. Prog Biophys Mol Biol 71: 435-478.

Schofield R (1978) The relationship between the spleen colony-forming cell and the haemopoietic stem cell. Blood Cells 4: 7-25.

Schwartz MA, Assoian RK (2001) Integrins and cell proliferation: regulation of cyclin-dependent kinases via cytoplasmic signaling pathways. J Cell Sci 114: 2553-2560.

Segawa Y, Muneta T, Makino H, Nimura A, Mochizuki T, Ju YJ, Ezura Y, Umezawa A, Sekiya I (2009)
Mesenchymal stem cells derived from synovium, meniscus, anterior cruciate ligament, and articular chondrocytes share similar gene expression profiles. J Orthop Res 27: 435-441.

Solchaga LA, Penick K, Porter JD, Goldberg VM, Caplan AI, Welter JF (2005) FGF-2 enhances the mitotic and chondrogenic potentials of human adult bone marrowderived mesenchymal stem cells. J Cell Physiol 203: 398409.

Solchaga LA, Penick K, Goldberg VM, Caplan AI, Welter JF (2010) Fibroblast growth factor-2 enhances proliferation and delays loss of chondrogenic potential in human adult bone-marrow-derived mesenchymal stem cells. Tissue Eng Part A 16: 1009-1019.

Spradling A, Drummond-Barbosa D, Kai T (2001) Stem cells find their niche. Nature 414: 98-104.

Swartz MA (2003) Signaling in morphogenesis: Transport cues in morphogenesis. Curr Opin Biotechnol 14: 547-550.

Takuwa N, Fukui Y, Takuwa Y (1999) Cyclin D1 expression mediated by phosphatidylinositol 3-kinase through mTOR-p70(S6K)-independent signaling in growth factor-stimulated NIH 3 T3 fibroblasts. Mol Cell Biol 19: 1346-1358.

Thorpe SD, Buckley CT, Vinardell T, O’Brien FJ, Campbell VA, Kelly DJ (2010) The response of bone marrow-derived mesenchymal stem cells to dynamic compression following TGF-beta3 induced chondrogenic differentiation. Ann Biomed Eng 38: 2896-2909.

Tschumperlin DJ, Dai G, Maly IV, Kikuchi T, Laiho LH, McVittie AK, Haley KJ, Lilly CM, So PT, Lauffenburger DA, Kamm RD, Drazen JM (2004) Mechanotransduction through growth-factor shedding into the extracellular space. Nature 429: 83-86.

Tufan AC, Daumer KM, DeLise AM, Tuan RS (2002) AP-1 transcription factor complex is a target of signals from both WnT-7a and N-cadherin-dependent cell-cell adhesion complex during the regulation of limb mesenchymal chondrogenesis. Exp Cell Res 273: 197-203.

Tulina N, Matunis E (2001) Control of stem cell selfrenewal in drosophila spermatogenesis by JAK-STAT signaling. Science 294: 2546-2549.

Von Wichert G, Jiang G, Kostic A, De Vos K, Sap J, Sheetz MP (2003) RPTP- $\alpha$ acts as a transducer of mechanical force on $\alpha \gamma / \beta 3$-integrin-cytoskeleton linkages. J Cell Biol 161: 143-153.

Watanabe N, Tezuka Y, Matsuno K, Miyatani S, Morimura N, Yasuda M, Fujimaki R, Kuroda K, Hiraki Y, Hozumi N, Tezuka K (2003) Suppression of differentiation and proliferation of early chondrogenic cells by Notch. J Bone Miner Metab 21: 344-352.

Wells RG, Discher DE (2008) Matrix elasticity, cytoskeletal tension, and TGF-beta: the insoluble and soluble meet. Sci Signal 1: pe13.

Wickham MQ, Erickson GR, Gimble JM, Vail TP, Guilak F (2003) Multipotent stromal cells derived from the infrapatellar fat pad of the knee, Clin Orthop Relat Res 412: 196-212.

Wozniak MA, Chen CS (2009) Mechanotransduction in development:a growing role for contractility. Nature Rev Mol Cell Biol 10: 34-43. 
Xie T, Spradling AC (1998) Decapentaplegic is essential for the maintenance and division of germline stem cells in the drosophila ovary. Cell 94: 251-260.

Xu Y, Malladi P, Chiou M, Bekerman E, Giaccia AJ, Longaker MT (2007) In vitro expansion of adiposederived adult stromal cells in hypoxia enhances early chondrogenesis. Tissue Eng 13: 2981-2993.

Zhang J, Li L(2008) Stem Cell Niche: Microenvironment and Beyond. J Biol Chem 283: 9499-9503.

Zhao JH, Reiske H, Guan JL (1998) Regulation of the cell cycle by focal adhesion kinase. J Cell Biol 143: $1997-$ 2008.

\section{Discussion with Reviewers}

Reviewer II: There are several studies showing that native cartilage ECM can have similar properties (Cheng et al., 2009, additional reference). How would the stem cell derived material compare to native cartilage with respect to cell-matrix interactions and maintenance of stemness? Authors: In one of our matrix studies (Pei et al., 2011, additional reference), we compared the proliferation and chondrogenic potential of SDSCs or chondrocytes after expansion on either DSCM deposited by SDSCs or chondrocytes. We found DSCM deposited by SDSCs provided a robust effect on the proliferation and chondrogenic capacity of either SDSCs or chondrocytes compared to ECM deposited by chondrocytes, suggesting that DSCM can provide a universal cell expansion system for cartilage tissue engineering using either stem cells or chondrocytes.

Reviewer II: The composition of the stem cell-derived material would seem to be critical to the observed effect on different cell types. What components appear to be the most important in this respect?
Authors: To the best of our knowledge, we are the first group working with DSCM that rejuvenates or reprograms expanded cell proliferation and chondrogenic differentiation. These findings are novel and exciting despite the fact that the work with DSCM is still in its infancy. We believe this concept is very important and will attract significant attention in the stem cell field; in particular, it will benefit cell-based tissue engineering and regeneration. Currently we have completed several studies and have published our data in peer-reviewed journals. In some of our studies, we characterized some DSCM components in which we were interested. For example, in He et al. (2009, text reference), in order to determine if cell expansion on DSCM yielding enhanced chondrogenic potential had any relationship with the components in ECM, we used histology and immunostaining. We evaluated the existence of sulfated GAGs, collagens I, II, and $\mathrm{X}$ and found that collagen I was the major component in DSCM deposited by SDSCs. However, we still do not have a complete picture of key components in DSCM that we can share with readers at this moment. We are confident that we can uncover this mystery in the near future.

\section{Additional References}

Cheng NC, Estes BT, Awad HA, Guilak F (2009) Chondrogenic differentiation of adipose-derived adult stem cells by a porous scaffold derived from native articular cartilage extracellular matrix. Tissue Eng Part A 15: 231241.

Pei M, He F, Wei L (2011) Three-dimensional cell expansion substrate for cartilage tissue engineering and regeneration: a comparision in decellularized matrix deposited by synovium-derived stem cells and chondrocytes. J Tissue Sci Eng 2: 104. 